\title{
LA OBRA NARRATIVA DE G. CABRERA INFANTE EN SUS RUPTURAS: EL LIBRO COMO POETICA DEL CUERPO
}

\author{
POR \\ MARIA GRAZIA BANNURA-SPIGA \\ Université de Paris, Vincennes
}

Numerosísimos son los autores y poetas quienes han sellado pactos con el pasado a través de reencuentros creativos, fundamentando así sus escrituras. Oponiéndose a la amputación de las remembranzas, persiguen una identidad, una unidad, tal vez ilusoria, imaginaria.

Guillermo Cabrera Infante intenta dar un contenido al ser gracias a las vueltas repetitivas e incansables a tiempos lejanos, remotos, de sus relatos. La memoria se estructura, en ellos, en la evocación de los cuerpos. Una división aparece en ella; el cuerpo se vuelve símbolo de la degradación y de la finitud en Así en la paz como en la guerra, Vista del amanecer en el trópico y Tres tristes tigres; en La Habana para un infante difunto es objeto de admiración. Sin embargo, la obra narrativa de Cabrera Infante se caracteriza por el hecho de que un cuerpo representa a todos los cuerpos. Para distinguirlos se trata de hacer coincidir esencia y apariencia física. Pero reproduciendo el mismo antagonismo de la representación, el cuerpo es asimilado al libro. Entre realidad y ficción, hecho a partir del recuerdo, tal vez sea el espacio imaginario privilegiado cuya pertenencia es en fin de cuentas incierta, indecible.

G. Cabrera Infante trata de focalizar, gracias a los narradores, la transición misteriosa, inefable, de la vida a la muerte a través de la imagen del cuerpo. Pone énfasis en lo inexplicable de la degradación, de la destrucción. En las viñetas de Así y Vista, el cuerpo varonil se halla comprometido, casi siempre, dentro de un proceso fatal, inexorable. La textualidad se edifica con y por los elementos físicos de los muertos. Mostrados como cadáveres anónimos, indiferenciados, los cuerpos de los difuntos se dejan ver a través de anotaciones que prueban su muerte o de metonimias que los desestructuran:

La sangre saltó bru sca y corrió por su cara y su pelo y se estancó bajo su cabeza, formando un charco. (Ast, p. 145)

Lo único vivo es la mano. Al menos la mano parece viva apoyada en el muro. No se ve el brazo y quizá la mano esté también mucrta. (Vista, p. 135)

La fragmentación o la anulación crean una cosmogonía funesta. El universo está asimilado a una tumba; la horizontalidad, la pasividad caracteri- 
zan el cuerpo que se manifiesta como un objeto alienado, aniquilado. Es una forma vaciada del hombre; sus acciones carecen de sentido, encarceladas en la repetitiva estructura de las viñetas. Pese a la cronología que ellas parecen seguir, reproducen en su seno una escena de violencia casi idéntica. Esta circularidad es reforzada por la intercambiabilidad y la adecuación no sólo de las épocas, sino también de los papeles de víctima y victimario.

La idea nietzscheana del eterno retorno se dobla de la visión panteísta de] ser humano. Más allá del texto de guerra, el cuerpo del muerto se vuelve plural, colectivo: resulta ser una reunión múltiple y heteróclita de otros difuntos, de miembros y órganos dedicados a la destrucción de otros miembros y órganos, negándole de este modo el estatuto de héroe.

El cuerpo discontinuo, y eterno a la vez, lleva en sí los signos patentes de una doble ruptura irremediable; la muerte interfiere en la evolución del tiempo narrativo y del ser mismo.

La interrupción que ella provoca se ve también inscrita en T.T.T., donde Bustrófedon y La Estrella aparecen a través de la obsesión de la ausencia; sus cuerpos fallecidos son reelaborados a lo largo de los relatos fracturados e indeterminados de T.T.T. Sólo pueden surgir como elementos fantasmagóricos en su estructura.

El proceso de desaparición y de fragmentación de la carne se percibe en la dimensión degradada del cuerpo sexual. Algunos cuentos de Así ponen en escena la prostitución ("Un rato de tenmeallá", "Josefina ..."), la culpabilidad ("En el gran Ecbó"), la indiferencia ("Cuando se estudia gramática"), como variantes de la problematización de las relaciones entre los personajes, la frustración llevando al fracaso todo esbozo de relación.

Este aspecto se repite en T.T.T. donde, a pesar de la multiplicidad de los intercambios amorosos, los cuerpos son igualados: Códac, Silvestre y Cué parecen formar diversas facetas de un mismo protagonista, y las mujeres que se suceden una a otra no se distinguen del todo. Ambos grupos son valorizados en cuanto objetos de consumo semejantes en la búsqueda irreprimible del placer. Forman una sola anatomía que nunca puede satisfacer. La posesión es efímera e impulsa hacia otros cuerpos que se reflejan unos a otros. Poseer un cuerpo es poseer todos los cuerpos. Esta circularidad que pone de relieve la decepción lleva a la desexualización: la vacuidad genera la ambigüedad, la ambivalencia de los géneros masculino y femenino. La noche que cubre T.T.T. no hace mas que aumentar la turbación, la confusión:

... y llegamos al Pigal y no bien entramos cuando se nos cruza Raquelita perdón. Manolito el Toro y viene y besa a Magalena y le dice Saludos mi amiga ... (T.T.T. p. 128)

La separación de los caracteres sexuales no es más respetada, alejando así el cuerpo de una definición segura, protectora; se vuelve caótico y privado de 
sentido. La transgresión del orden moral expresa lo inaccesible de la identidad y la inadaptación a esquemas tradicionales. El cuerpo se transforma en un medio para huir momentáneamente de la realidad funesta; pero el erotismo une sexo y muerte, indicando sólo dispersión y destrucción. En sus dispositivos monótonos, la creencia en el sexo lleva a un callejón sin salida.

La representación de la seducción pasajera en La Habana implica el acercamiento al cuerpo visto como objeto de deseo lúdico. Juegos e ironía anticipan el placer esperado por el narrador-actor, delimitando el aspecto sagrado de los cuerpos exaltados.

El espacio textual es invadido por las fisonomías femeninas, puesto que el discurso se apodera de una serie de retratos precisos puestos de relieve en su hermosura. Bajo la mirada del narrador, todos los elementos físicos adquieren resplandor y vitalidad. Maravillado, cautivado por el aspecto deslumbrador de los cuerpos, comunica su embeleso gracias al humor, el vocabulario popular:

La sola visión de aquel desnudo que todavía me parece ideal (color, carne, cuerpo) me curó de mi catarro y de mi acidia. (La Habana, p. 116)

Pero cuando Beba (...) salió sonriente del agua, el chapuzón se hizo charco (...): verla fue ver surgir (...) a Venus de entre las olas. Me pareció que nunca hab́́a visto una mujer tan bella. (La Habana, p. 301)

Se hablaba de la belleza de Julieta de la perfección de su cuerpo, de sus senos sagrados, de sus muslos dorados que encajaban en caderas bien torneadas. ( $L a$ Habana, p. 424)

Violeta tenía unas tetas provocativas que llamaban mucho la atención y su cuerpo era muy de hembra y llevaba además su cara bella. (id, p. 565)

A pesar de la diversidad de los personajes, son los mismos adjetivos que, reiteradamente, los califican e igualan sus cuerpos en su espectáculo embrujador. Pertenecen al campo semántico de las exclamaciones artísticas, subjetivas. La repetición de los superlativos corresponde quizás a cierta impotencia en definir la variación particular de cada fisonomía. A través del estereotipo de la belleza, se trata de expresar sin éxito sensaciones pasadas que llegan a confundirse. Al tratar de restituir el eros al centro de la escritura, el narrador sólo consigue enfrentarse con la imposibilidad de comunicar la peculiaridad de cada experiencia. Como dice Rolland Barthes: "On échoue toujours à parler de ce qu'on aime" ${ }^{\text {. }}$.

El cuerpo se vuelve el representante de todos los cuerpos. Encierra en él una multitud de fragmentos. Para fundamentar una diferenciación entre fisonomias, se propone configurar a la vez la parte material del personaje y su espíritu. En la dualidad o la unión de la apariencia y de la esencia, el cuerpo, hecho antítesis o reflejo, tiene la ilusión de volverse único, particular, compren. sible.

${ }^{1}$ R. Barthes: Le bruissement de la langue (Paris: Ed. du Seuil, 1984) 333. 
EnT.T.T., las figuras femeninas exiben una ambivalencia entre la armonía frágil de su aspecto físico y la ausencia de todo contenido ontológico. Los encantos del cuerpo disimulan la vacuidad interior. La imagen que aparentan las formas llenas ostenta una negación de la autenticidad: máscaras y artificios les permiten esconder su superficialidad, su falsedad. El cuerpo se transforma en disfraz, en trampa seductora.

La Estrella rompe con el estereotipo de la belleza externa; el carácter hiperbólico de su fisonomía, sus dimensiones hipertrofiadas, sus mensuraciones extraordinarias, la asimilan a una deidad primitiva. Su cuerpo encierra, en su profusión, algo esencial, absoluto: su voz que simboliza lo verdadero. Oponiéndose a los valores estéticos de la apariencia superficial, se vuelve un punto de referencia.

También La Habana enfoca detenidamente los cuerpos de los personajes de mujeres, quienes, sin falso pudor, polarizan la exacerbación de los sentidos y la perfección. Si no muestran un antagonismo entre características físicas y dimensión interior como en T.T.T., los cuerpos en La Habana no logran ser totalmente emanaciones del alma, encerrando en ellos mismos sus contradicciones, sus enigmas.

Lejos de utilizar alusiones o elipses, el narradoractor se aproxima a la intimidad de los cuerpos tratando de esta manera de definir los protagonistas. Sus nombres y apellidos indican la posibilidad de esta adecuación:

Ninguno de nosotros acertó entonces su verdadera naturaleza: Isabel Miranda, la doctora Miranda, era admiranda, lo sé ahora, una exhibicionista extraordinaria. (La Habana, p. 399)

Sin embargo, se realiza sólo en la formación de una morfología de un modelo absoluto. A través de la regularidad y simetría de las formas, el narrador exal ta la gracia y la delicia de la anatomía en su representación imaginaria. El aspecto físico se transforma en el espejo de la mente en su reelaboración: el recuerdo lo vuelve mítico. Los personajes son deidades, "diosas", como lo indica S. Merrim².

La veneración panteísta elabora un cuerpo sin edad en la memoria de los ritos y ceremoniales amorosos. Espacio positivo, permite al narrador encaminarse en la vía del conocimiento de la carne, del verbo.

La fisonomía es un discurso que empuja hacia la búsqueda de la profundidad del ser, del lenguaje perdido. Por ser inacabable, inabarcable, la definición del cuerpo y de su contenido psicológico sólo puede ser parcial en el infinito del deseo, del gozo. Materia en movimiento perpetuo, vacila entre realidad y ficción.

Los cuerpos, como el texto, necesitan de la memoria para surgir de nuevo, renacer en las palabras. Brotan del pasado, reelaborados por las rememoraciones de los narradores. La lucha en contra del olvido, del pasar del tiempo, se realiza por medio de la escritura, otorgándoles una dimensión utópica, ficticia.

2S. Merrim: "La Habana para un infante difunto y su teoría topográfica de las formas", Revista Iberoamericana, № 118-119 (ene.-jun., 1982): 405. 
Según I. Alvarez Borland, "Rompecabezas" y "La muerte de Trotsky”, en T.T.T., se asemejan a "una oración fúnebre o encomio a un personaje ya desaparecido"s. Bustrófedon, puesto que se trata de él, como La Estrella, obtienen una perduración gracias a las remembranzas de los personajes que los evocan. Como en Así y Vista, la narración establece un puente entre pasado y presente, asegurando la supervivencia de los cuerpos ausentes. Permite resolver el problema existencial sobrepasando la muerte y dando un contenido ontológico a los fallecidos. Idealizados por la distancia temporal, reproducen la misma contradicción que la de la escritura: se refieren a una "realidad" alejándose a la vez de ella para constituir un microcosmo autónomo.

En La Habana, el cuerpo como escritura se inscribe también a través de los recuerdos. Se vuelve un código lúdico, una estructura rítmica donde lo sensual está directamente ligado a las pulsiones e impulsiones de la memoria. La aventura del cuerpo permite el viaje en el lenguaje, la exploración de zonas erógenas en la escritura; como lo indica E. Rodríguez Monegal: "Las conquistas (o derrotas) cuentan menos que la infinita memoria del sexo como escritura ${ }^{5 / 4}$.

Los cuerpos de las protagonistas, asimilados a la materia literaria gracias a las reminiscencias, llevan la marca de las preocupaciones estéticas, filosóficas, del autor: vehiculan, en su sistema armonioso, la búsqueda de la belleza - la mirada de lo ideal-, de la esencia del lenguaje - la palabra como espejo-, integrando el aspecto dual de tal propósito. Tanto la belleza como el lenguaje se enfrentan a la imposibilidad de ser reflejados y de ser restituidos. Ellos mismos imitan, pero no encarnan la realidad pese a la acumulación de elementos verosímiles. El personaje de Margarita del Valle en La Habana tiene aparentemente un cuerpo perfecto, pero su fisonomía disimula una mutilación: ésta simboliza la parte oscura, impenetrable del ser visto en su fragmentación. El cuerpo, como la escritura, es el edén soñado, espacio privilegiado y mítico, visión prototípica del deseo.

La carne condena, nos lleva a su contemplación, a su adoración y es nuestra versión del paraíso. (La Habana, p. 571)

Utopía nostálgica, inexplicable en la atracción que provoca, el cuerpol discurso se vuelve religión; culto y doctrina pagana, reemplaza lo divino por el ceremonial de la sensualidad de las palabras, de las anatomías.

Las representaciones de los cuerpos en la obra de Guillermo Cabrera Infante traducen una serie de tentaciones y de tentativas para trasladar en ellas una definición del ser. La diferenciación entre las fisonomias se vuelve irrealizable, puesto que la identidad es un trabajo de delimitación y, queriendo

\footnotetext{
${ }^{3}$ I. Alvarez-Borland, Discontinuidady ruplura en G. Cabrera Infante (Ed. Hispamérica) 94.

${ }^{4}$ E. Rodríguez Monegal: "Cabrera Infante: la novela como autobiograffa total". Revista Iberoamericana № 116-117 (jul.-dic. 1981): 270.
} 
igualar límites externos y límites internos, es imposible fundamentarla. La problemática de la complementariedad ideal entre apariencia y esencia se enfrenta, además, al hecho de que Cabrera Infante pone en escena fantasmas o dobles que huyen de toda posesión definitiva. Los cuerpos no revelan su misterio. En Así, Vista y T.T.T., la fragmentación que los caracteriza impide toda transcripción decisiva; La Habana enfoca el personaje principal en lo incompleto de su formación, a través de experiencias múltiples. La utilización de anacronismos y rupturas de la memoria agudizan aún más el aspecto inacabado, inmaduro del protagonista y de su discurso.

Cuerpo y texto se confunden en el intento de establecer una ficción del ser. La Habana es el único libro que introduce el placer en la restitución de los cuerpos como espacios eróticos. Anatomía y relato arquetípicos escapan a toda clasificación gracias a lo lúdico; el narrador-actor se vuelve mirón del espectáculo ofrecido por el texto/cuerpo y el lector se transforma en su cómplice, integrando así la estructura de juegos de La Habana. Se puede recordar la frase de R. Barthes: "Le texte à une forme humaine, c'est une figure, un anagramme du corps? Oui, mais de notre corps érotique ${ }^{35}$.

El cuerpo siente fascinación y rechazo por la perfección del texto, su doble. Quiere a la vez rozar el espacio vertiginoso de la eternidad, de lo inmutable, y permanecer en el dominio de lo carnal, de la imperfección. Entre estas dos tensiones incompatibles, el cuerpo y el texto se funden para sobrepasarlas: capturan lo breve de un instante en el cual la corrupción desafía lo que es destinado a ser duradero. Se transforman en la ceremonia de una imagen, de una transcripción fugaz e imperecedera a la vez.

${ }^{5}$ R. Barthes, Le plaisir du texte (Paris: Ed. du Seuil, 1973) 30. 
REFERENCIAS A LA OBRA DE G. CABRERA INFANTE

Así en la paz como en la guerra (Barcelona: Seix Barral, 1974).

Vista del amanecer en el trópico (Barcelona: Seix Barral, 1974).

Tres tristes tigres (Barcelona: Seix Barral, 1967).

La Habana para un infante difunto (Barcelona: Seix Barral, 1979). 
